\title{
CONSUMER VULNERABILITY IN PHARMACEUTICAL MARKET: CASE OF BALTIC COUNTRIES
}

\author{
Borisas Melnikas ${ }^{1}$, Rasa Smaliukiene் ${ }^{2}$ \\ International Economics and Management Department, Vilnius Gediminas Technical University, \\ Sauletekio al.11, 10223 Vilnius, Lithuania.E-mail: ${ }^{1}$ melnikas@vv.vtu.lt; ${ }^{2}$ rasasmal@vv.vtu.lt
}

Received 5 September 2006; accepted 4 December 2006

\begin{abstract}
Consumer vulnerability receives attention in search for effective solutions of complex problems in the social welfare system on the international as well as local or regional scale. Pharmaceutical consumer vulnerability takes various forms and therefore it may be analyzed in social, economic, legal, ecological or purely medical terms. The article presents an integrated methodology that was applied to develop an indicator of pharmaceutical consumption and pharmaceutical consumer vulnerability; it also presents findings of the research, which employed this methodology to estimate vulnerability of different consumer groups as well as general consumer vulnerability in Lithuania, Latvia and Estonia.
\end{abstract}

Keywords: consumer vulnerability, pharmaceuticals, Baltic countries.

\section{Introduction}

Pharmaceutical consumer vulnerability is a rather controversial phenomenon of the contemporary society. This phenomenon is growing in scale and is becoming more complex and threatening. It requires consistent monitoring, and that means that it has to be analyzed in view of newly emerging situations and circumstances. Research into vulnerability of pharmaceutical consumers is absolutely essential. Its importance today is obvious for several reasons.

Firstly, the importance of research into pharmaceutical consumer vulnerability is determined by processes of globalization and market integration, which have a direct impact on manufacturing and consumption of pharmaceuticals. The majority of pharmaceuticals are already marketed internationally and that significantly increases probability that consumer vulnerability in general as well as vulnerability of consumers to certain pharmaceuticals may appear on an international scale. Another peculiarity of globali- zation is heavy concentration of pharmaceutical manufacturing and merging of pharmaceutical manufacturers: globalization brings market expansion and that provokes spring of mergers which then operate internationally, and that means that vulnerability of pharmaceutical consumers will be largely determined by large pharmaceutical businesses. Furthermore, globalization fosters other new conditions previously unknown or of little importance: these new conditions and circumstances require a new approach to consumer vulnerability in the context of globalization. Thus, processes of globalization and market integration and their impact should be viewed as a very important factor, which predetermines the necessity of a research into pharmaceutical consumer vulnerability.

Secondly, vulnerability of pharmaceutical consumers is increasingly more influenced by more rapid scientific and technological advancement and changes in lifestyle. The world, as we know, is witnessing very rapid changes in pharmaceutical business - new man- 
ufacturing and treatment technologies and new drugs emerge all the time, and that may cause, new and previously unknown forms of consumer vulnerability: new pharmaceuticals may spread much more rapidly than different preventative and safety measures [1]. This reason also explains the key role of research into pharmaceutical consumer vulnerability, which takes into account rapid but rather controversial scientific and technological advancement.

Thirdly, new forms of consumer social vulnerability spring up. The modern society witnesses the growing socio- economic differentiation which takes new forms and is observed in separate countries or regions as well as internationally. The cost of living and purchasing power differ a lot in various countries where the same pharmaceuticals are marketed, and that certainly has an impact on consumer vulnerability [2]. In addition to this, different countries pursue rather different state policies in the field of pharmacy and in health care in general. All this predetermine the necessity of rather specific and constantly renewed researches aimed at establishing dependence of consumer vulnerability upon various forms of socio-economic differentiation of a society. This aspect is of special importance in the countries of Central and Eastern Europe: socio-economic developments in these countries foster growing socio-economic and perceptional differentiation [3], and that has a direct impact on consumption of pharmaceuticals and pharmaceutical consumer vulnerability.

It may be assumed that reduction of pharmaceutical consumer vulnerability in the context of growing socio-economic differentiation is an important issue of health care and also a basic prerequisite for reduction of social tension in the society: it is obvious that the situation when people can not afford new effective but expensive pharmaceuticals creates social tension which takes various forms, including aggressive behavior and other dangerous forms. Furthermore, inaccessibility of drugs due to high prices often gives birth to socially unacceptable and even health-threatening behavior, as alcoholism, drug addiction, etc.

Being aware of the importance of research into pharmaceutical consumer vulnerability, we should set a priority of analysis of pharmaceutical business development opportunities in different countries and regions with the view to the necessity to protect pharmaceutical consumers from various vulnerabilities, which are fostered by business globalization, more rapid scientific and technological advancement and greater socio-economic differentiation of the society in one or another country or between several different countries or regions.

The vulnerability amongst the consumers in a pharmaceutical market is actualised in many articles and conceptualised in two directions. Researchers who analyse the social vulnerability of elderly people or youth to medicine represent the first direction. Usually they emphasize the problems of self-medication or prescribing practice $[4,5,6]$. The second direction is represented through the analyses of the economic effect on medication and the cost-benefit of the pharmaceutical reimbursement system [7, 8, 9]. However, previous research in these two directions is incomprehensible and pays little attention to the complexity of the problem.

The main goal of the research in this field is to create preconditions for further development of pharmaceutical business that would go in line with reduction of pharmaceutical consumer vulnerability. Such research is of great importance to all countries and regions, but first of all to East European countries: these countries are undergoing rapid processes of economic, social and cultural integration and therefore it is especially important to ensure that development of pharmaceutical business in these countries guarantees safety to pharmaceutical consumers; it acquires economic, social and even political meaning - degree of pharmaceutical consumer vulnerability is one of basic indicators showing the society's ability to live full life in the Western world.

For all the above reasons a research was conducted into vulnerability of pharmaceutical consumers in Baltic countries. The research had the following two objectives:

- to analyze the attitude to development of pharmaceutical business in modern theories, paying attention to the factors which determine vulnerability of consumers to pharmaceuticals; to evaluate suitability of these theories in development of pharmaceutical business in modern conditions and especially in the context of transformational processes in Eastern Europe, globalization and market internationalization;

- to identify the main reasons of pharmaceutical consumer vulnerability typical for East European countries undergoing transformations and to assess possibilities to reduce this vulnerability with the view to specific characteristics of the transformational period. 


\section{Concept of pharmaceutical consumer vulnerability and its reflection in modern theories}

Pharmaceutical consumer vulnerability is a concept that describes a complex and controversial phenomenon of the modern society development. The essence of the phenomenon is that continuous growth of consumption on the world scale not only evidences advancement of pharmacy and pharmaceutical practice but also characterizes growing pharmaceutical consumer vulnerability. This vulnerability is caused by:

- various adverse physical effects which emerge as the consumption of pharmaceuticals grows;

- growing additional risks due to improper preparation for use of various, especially new, pharmaceuticals;

- social and psychological factors which take place at different stages of pharmaceutical activity and pharmaceutical business.

Introduction and use of the concept of pharmaceutical consumer vulnerability shows that consumption of pharmaceuticals is closely related to consumer vulnerability as well as with adverse effects caused by wide spread and consumption of pharmaceuticals.

Introducing the concept, defining it and using it in practice is necessary for targeted and constructive implementation of measures for realistic reduction of adverse effects which are caused, or may be caused, by pharmaceutical consumer vulnerability. It is highly important to understand, interpret and assess this concept relevantly to the real situation in modern pharmacy and health care. That is why it is necessary to discuss this concept in greater detail and to define it more clearly.

Many scholars have analyzed the concept of pharmaceutical consumer vulnerability, various interpretations may be found in scientific publications [10, 11]. Seeking for systemic approach to consumer vulnerability in different fields of life, all the works may be grouped into several sets. Lee and Soberon-Ferrer [12] single out cognitive deficiency and social interaction paradigms, the first including consumer age, education, knowledge and experience, the lattersociability and social exclusion of an individual consumer from the group he belongs to. Pharmaceutical consumer vulnerability is also dealt with in works of different fields of science; a special place among them should be rewarded to scientific works in social marketing and social communications.

In terms of problem formulation and identification the most worthy are the following definitions of pharmaceutical consumer vulnerability:

- Benets, Pitts, LaTour [13] and Andreasen, Manning [14] fined socially vulnerable market segment as a group with higher than usual marketing vulnerability,

- Morgan, Schuler and Stoltman [15] defined socially vulnerable consumers as a group of consumers who have idiosyncratic reactions to products that are otherwise harmless when used by most people.

- Smith and Cooper-Marti [16] defined socially vulnerable consumers as those who are more susceptible to economic, physical or psychological harm in, or as a result of, economic transformations because of characteristics that limit their ability to maximize their utility and well being.

- Ringold [17] proposed that vulnerable consumers fail to understand their preferences and/or lack the knowledge, skills, or freedom to act on them.

It has been estimated that social vulnerability of the market depends on such inner factors as physical competency, mental competency, and level of sophistication [15]. All these factors are important when trying to analyze pharmaceutical consumer vulnerability; however, special attention should be paid to physical competency, which gradually deteriorates as the symptoms of the illness against which pharmaceuticals are purchased get more persistent. Social vulnerability of the market is also determined by such factors as consumers' susceptibility to economic and psychological impact that limits their ability to maximize their utility.

In addition to this, pharmaceutical consumer vulnerability is caused not only by social vulnerability of the market but also by factors closely related to the product itself. Unlike other products, pharmaceuticals, while having positive effect on human body functions, also have a negative side. This negative effect can be of three types - physical, economic and psychological [16]. These effects usually emerge after a consumer has purchased and consumed the product; however, accessibility to pharmaceuticals is another factor of no less importance. Widdus [18] points out two groups of factors that determine accessibility to pharmaceuticals - suitability and availability. The first group of factors includes those, which ensure products' suitability for consumption (i.e. reliable survey research, testing, effective managerial activity, manufacturing and marketing). The second group of factors characterize realistic conditions in which pharmaceuticals are consumed; this group includes such 
concepts as quality insurance, rational selection, proper prescription and rational application, efficiency of distributional system, economic factors (sources of financing, expenditure, pricing policy and control), consumer awareness and consumer orientation to healthy living.

In view of various approaches to the concept of pharmaceutical consumer vulnerability, the following definition is suggested: pharmaceutical consumer vulnerability is a quality of pharmaceutical consumers that is observed when a consumer uses, or intends to use, pharmaceuticals, which expresses a possibility and a probability that the pharmaceutical products will not bring an expected positive result and that the use of those products may have adverse reactions, or that consumers may experience inaccessibility to these products which at the same time is violation of human rights to healthcare.

This definition of pharmaceutical consumer vulnerability could be viewed as general and universal, as it applies to different life situations and different aspects of consumer vulnerability. As it is a basically new definition, it requires some additional comments.

\section{Method}

In order to have a many-sided integral research into pharmaceutical consumer vulnerability, sociological research was conducted simultaneously. In the course of the research respondents were surveyed, by filling in a questionnaire. Respondents included (1) representatives of the main strata of the society, who regularly use various pharmaceuticals; (2) doctors of different specialization who provide recommendations to consumers of pharmaceuticals regarding their usage; (3) specialists working in the field of pharmacy.

This study was conducted several times over the period of 1992-2005; most of the surveying was conducted in Lithuania, some in Latvia and Estonia. Findings of the study should be viewed as common for all three countries, the more so that the situation in these countries in terms of consumer vulnerability is very much alike.

Seeking to gain credibility of findings, the researchers ensured an adequate number of respondents. The researchers tried to find out opinions of different groups of respondents on consumption of pharmaceuticals and pharmaceutical consumer vulnerability. This study was performed at four stages:

The first stage - working out criteria to measure pharmaceutical consumption and pharmaceutical consumer vulnerability and grading their weight in the scale from 0 to 10 ; the weight of each criterion was differentiated for each group of respondents, i.e. each group of respondents had a different scale of criteria weight.

The second stage - each respondent individually assessed consumption of pharmaceuticals and pharmaceutical consumer vulnerability according to different criteria: the scale of assessment was $0-10$; individual assessments disclosed some regularities in assessing pharmaceutical consumer vulnerability, typical to different groups of respondents. Moreover, at this stage average assessment according to each of the criteria was worked out and weight of those average assessments was calculated.

The third stage - experts evaluated weight of each group of respondents. Experts took into consideration each group's ability to provide objective assessment of the situations and factors related to problems of pharmaceutical consumer vulnerability. Each group was evaluated on the scale from 0 to 10 .

The fourth stage - analysis of empirically established correlation between various indicators characterizing pharmaceutical consumption and pharmaceutical consumer vulnerability, and various characteristics of consumers.

The final outcome of the research is an integrated indicator of pharmaceutical consumption and pharmaceutical consumer vulnerability, expressed by the formula:

$$
C=\frac{\sum_{r=1}^{R} A_{r} C_{r}}{\sum_{r=1}^{R} A_{r}},
$$

where $C$ is an integrated indicator of pharmaceutical consumption and pharmaceutical consumer vulnerability within one country or region at a specific year (or any other period), $C_{r}-$ corresponding integrated indicator, typical to one group of respondents $r(r=1,2,2, \ldots$, $R), A_{r}$ - weight of the respondent group.

Furthermore, integrated indicators of pharmaceutical consumption and pharmaceutical consumer vulnerability, typical to one or another group of respondents, are expressed by the formulae:

$$
C_{g}=\frac{\sum_{p=1}^{P} \sum_{k=1}^{K} B_{k r} C_{k p}}{P \sum_{k=1}^{K} B_{k r}},
$$


where $C_{k p}$ is assessment of pharmaceutical consumer vulnerability made by a respondent $p(p=1,2$, $3, \ldots, P)$, who belongs to a respondent group $r(r=$ $1,2,3, \ldots, R)$, according to the criteria $k(k=1,2$, $3, \ldots, K), B_{k r}$ is weight of the criteria $k(k=1,2,3, \ldots$, $K)$ in the respondent group $r(r=1,2,3, \ldots, R), P-$ total number of respondents in the group $r(r=1,2$, $3, \ldots, R)$.

The above-mentioned assessments of pharmaceutical consumption and pharmaceutical consumer vulnerability were made as a result of empirical researches at different stages over the period 1992-2005. It is the findings of 2005 that are given as examples in this article, as they are relevant to the present situation in the Baltic countries.

\section{Results}

The results show (Table 1) that the main criteria that determine pharmaceutical consumer vulnerability are: inaccessibility of pharmaceuticals, adverse reactions of pharmaceuticals and various pressures that they experience. The most important of these criteria are inaccessibility of pharmaceuticals, adverse reactions and advertising; consumer vulnerability is lower when a doctor or a pharmacist prescribes the product. In view of the findings of the market transactions analysis, which show doctors' and pharmacists' high susceptibility to commercial information, their influence was also given some, though not big, weight. The research findings suggest that doctors and pharmacists themselves do not think that their work could increase consumer vulnerability and thus the weight of the corresponding indicators is $0-0.001$.
Having set pharmaceutical consumer vulnerability criteria and their weight, a sequent stage of the research was carried out, where the respondents represented different social classes and were characterized as regular users of pharmaceuticals. In the course of the research it was established that the main factors that influence consumers' needs and ability to use pharmaceuticals, are the following: (1) consumers' health, (2) consumers' age, (3) consumers' income.

Findings of interviews show that all these factors are of crucial importance for the amount of purchased pharmaceuticals, which is evident from consumers' spending on pharmaceuticals. Correlation of these factors is presented in Table 2. In addition to the above factors, sometimes the amounts purchased may also depend on other factors - education, type of job, marital status; however, in terms of pharmaceutical consumer vulnerability, influence of these factors can be viewed as inessential. Analysis of the major factors that can affect pharmaceutical consumer vulnerability revealed specific development tendencies in the Baltic countries.

It was established that consumers' health is one of the major factors affecting the need to purchase and consume pharmaceuticals. Disabled consumers and consumers suffering from chronic diseases who continuously consume drugs create especially favorable conditions for development of pharmaceutical business. The research established that there is a direct correlation between consumers' health and consumption of pharmaceuticals ( $r=0.632, p=0)$. Many researchers have emphasized correlation between consumers' health and expenditure on health care, e.g. Batavia and Beaulaurier [10] pointed out financial

Table 1. Pharmaceutical consumer vulnerability criteria and their weight

\begin{tabular}{|c|c|c|c|c|c|c|c|c|}
\hline \multirow[b]{2}{*}{ Vulnerability criteria } & \multirow{2}{*}{$\begin{array}{l}\text { Criteria } \\
\text { weight }\end{array}$} & \multicolumn{7}{|c|}{ Spread of criterion weight } \\
\hline & & Physician & Consultants & Extern & $\begin{array}{l}\text { Other } \\
\text { doctors }\end{array}$ & Pharmacists & Wholesalers & $\begin{array}{c}\text { Drug- } \\
\text { manufacturing }\end{array}$ \\
\hline $\begin{array}{l}\text { Economic inaccessibility } \\
\text { of pharmaceuticals }\end{array}$ & 0,384 & 0,248 & 0,437 & 0,217 & 0,397 & 0,493 & 0,559 & 0,177 \\
\hline $\begin{array}{l}\text { Adverse reactions } \\
\text { caused by } \\
\text { pharmaceuticals }\end{array}$ & 0,287 & 0,402 & 0,283 & 0,403 & 0,208 & 0,184 & 0,129 & 0,211 \\
\hline \multicolumn{9}{|l|}{ Motives of purchasing: } \\
\hline - doctor's prescription & 0,003 & 0,001 & 0 & 0 & 0,005 & 0,008 & 0,001 & 0,001 \\
\hline - pharmacist's advice & 0,005 & 0,008 & 0,01 & 0,016 & 0,001 & 0,01 & 0,005 & 0,005 \\
\hline - brand awareness & 0,015 & 0,01 & 0,009 & 0,013 & 0,094 & 0,141 & 0,09 & 0,09 \\
\hline - advertising & 0,216 & 0,27 & 0,2 & 0,288 & 0,195 & 0,008 & 0,195 & 0,195 \\
\hline - other people's advice & 0,09 & 0,061 & 0,061 & 0,063 & 0,1 & 0,156 & 0,021 & 0,321 \\
\hline Total: & 1 & 1 & 1 & 1 & 1 & 1 & 1 & 1 \\
\hline
\end{tabular}


Table 2. Inter-correlation of characteristics of pharmaceutical consumers

\begin{tabular}{|c|c|c|c|c|c|}
\hline & Age & $\begin{array}{c}\text { Spending on } \\
\text { pharmaceuticals }\end{array}$ & $\begin{array}{c}\text { Annual income } \\
\text { per head in the } \\
\text { family or per } \\
\text { capita }\end{array}$ & Health problems & $\begin{array}{c}\text { Purpose of } \\
\text { pharmaceuticals } \\
\text { purchased }\end{array}$ \\
\hline \multicolumn{6}{|l|}{ Correlation coefficients (r) } \\
\hline age & 1,000 & 0,305 & 0,070 & 0,348 & 0,178 \\
\hline $\begin{array}{r}\text { Spending on } \\
\text { pharmaceuticals }\end{array}$ & 0,305 & 1,000 & 0,155 & 0,632 & 0,233 \\
\hline $\begin{array}{r}\text { Annual income per head in } \\
\text { the family or per capita }\end{array}$ & 0,070 & 0,155 & 1,000 & 0,168 & 0,360 \\
\hline Health problems & 0,348 & 0,632 & 0,168 & 1,000 & 0,521 \\
\hline $\begin{array}{r}\text { Purpose of the } \\
\text { pharmaceuticals purchased }\end{array}$ & 0,178 & 0,233 & 0,360 & 0,521 & 1,000 \\
\hline \multicolumn{6}{|l|}{ Weight $(\mathrm{p})$} \\
\hline age & , & 0,000 & 0,031 & 0,000 & 0,000 \\
\hline $\begin{array}{r}\text { Spending on } \\
\text { pharmaceuticals }\end{array}$ & 0,000 & , & 0,000 & 0,000 & 0,000 \\
\hline $\begin{array}{r}\text { Annual income per head in } \\
\text { the family or per capita }\end{array}$ & 0,031 & 0,000 & , & 0,000 & 0,000 \\
\hline Health problems & 0,000 & 0,000 & 000 & , & 0,000 \\
\hline $\begin{array}{r}\text { Purpose of the } \\
\text { pharmaceuticals purchased }\end{array}$ & 0,000 & 0,000 & ,000 & 0,000 & , \\
\hline
\end{tabular}

vulnerability of the disabled. Other motives that encourage consumers to buy pharmaceuticals include a wish to stay healthy, a wish to get rid of unhealthy habits and a wish to look better. However the number of respondents who named these factors as stimulating to buy pharmaceuticals is insignificant.

Poor health condition just determines a seek to be healthy, while external factors create a need to buy a specific pharmaceutical product. Empirical research, based mainly on consumer survey, enabled to distinguish the major factors, which affect consumers' needs and choice of pharmaceuticals. These factors are as follows: (1) doctor's prescription, (2) pharmacist's recommendation, (3) other people's advice, (4) advertising, (5) brand awareness.

The weight of these factors was determined by surveying consumers. The findings suggest (see Table 3 ) that it is advertising that has the most powerful effect on consumers' decisions: $34 \%$ of respondents confirmed the influence of advertising. Brand awareness and advice of other people also influence independent decision making ability. Independent choice of drugs and their consumption without specialists' guidance or supervision constitute probably the greatest danger in the practice of drug consumption. More than half $(54 \%)$ of consumers in the Baltic countries choose (prescribe to themselves) drugs and that re- flects extreme consumer vulnerability. Advertising, as the most biased information source, is most influential to people aged 46-65 (Table 3). This influence does not depend on any other characteristics, which means that such factors as education and higher than average income cannot protect consumers from potential risks to their health.

Consumers' age also has some direct impact on the amounts of pharmaceuticals purchased. It is only natural that aging people have a higher need for pharmaceuticals, which is confirmed by established direct correlation between consumers' age and their expenditure for pharmaceutical products $(r=0,305$, $p=0)$.

Monthly spending on pharmaceuticals depends on annual income. The degree of correlation is not high $(r=0,15)$, because persons with chronic diseases and the disabled receive low income but spend disproportionately much on drugs. It is also noteworthy that consumers with low or average income are indifferent to pharmaceuticals for maintaining healthy state and only $7,8 \%$ of these consumers were using such pharmaceuticals during the research. Meanwhile, consumers with high income spend much more on such pharmaceuticals and the research found out that most of them $(58,1 \%)$ were taking preventative products for maintaining or improving their health 
Table 3. Respondents' distribution according to age and the influence on decision making to purchase pharmaceuticals

\begin{tabular}{|c|c|c|c|c|c|}
\hline Influence & Age & Frequency & Valid Percent & Percent & $\begin{array}{c}\text { Cumulative } \\
\text { Percent }\end{array}$ \\
\hline \multirow[t]{7}{*}{$\begin{array}{l}\text { Doctor's } \\
\text { prescription }\end{array}$} & under 25 & 29 & 17,3 & 17,3 & 17,3 \\
\hline & $26-35$ & 26 & 15,5 & 15,5 & 32,7 \\
\hline & $36-45$ & 42 & 25,0 & 25,0 & 57,7 \\
\hline & $46-55$ & 14 & 8,3 & 8,3 & 66,1 \\
\hline & $56-65$ & 17 & 10,1 & 10,1 & 76,2 \\
\hline & over 66 & 40 & 23,8 & 23,8 & 100,0 \\
\hline & Total & 168 & 100,0 & 100,0 & \\
\hline \multirow[t]{7}{*}{ Pharmacist's advice } & under 25 & 66 & 25,5 & 25,5 & 25,5 \\
\hline & $26-35$ & 44 & 17,0 & 17,0 & 42,5 \\
\hline & $36-45$ & 74 & 28,6 & 28,6 & 71,0 \\
\hline & $46-55$ & 38 & 14,7 & 14,7 & 85,7 \\
\hline & $56-65$ & 26 & 10,0 & 10,0 & 95,8 \\
\hline & over 66 & 11 & 4,2 & 4,2 & 100,0 \\
\hline & Total & 259 & 100,0 & 100,0 & \\
\hline \multirow[t]{7}{*}{ Brand awareness } & under 25 & 24 & 26,1 & 26,1 & 26,1 \\
\hline & $26-35$ & 13 & 14,1 & 14,1 & 40,2 \\
\hline & $36-45$ & 7 & 7,6 & 7,6 & 47,8 \\
\hline & $46-55$ & 7 & 7,6 & 7,6 & 55,4 \\
\hline & $56-65$ & 20 & 21,7 & 21,7 & 77,2 \\
\hline & over 66 & 21 & 22,8 & 22,8 & 100,0 \\
\hline & total & 92 & 100,0 & 100,0 & \\
\hline \multirow[t]{7}{*}{ Others' advice } & under 25 & 9 & 22,0 & 22,0 & 22,0 \\
\hline & $26-35$ & 7 & 17,1 & 17,1 & 39,0 \\
\hline & $36-45$ & 10 & 24,4 & 24,4 & 63,4 \\
\hline & $46-55$ & 7 & 17,1 & 17,1 & 80,5 \\
\hline & $56-65$ & 3 & 7,3 & 7,3 & 87,8 \\
\hline & over 66 & 5 & 12,2 & 12,2 & 100,0 \\
\hline & total & 41 & 100,0 & 100,0 & \\
\hline \multirow[t]{7}{*}{ Advertising } & under 25 & 44 & 11,5 & 11,5 & 11,5 \\
\hline & $26-35$ & 79 & 20,6 & 20,6 & 32,1 \\
\hline & $36-45$ & 62 & 16,2 & 16,2 & 48,3 \\
\hline & $46-55$ & 85 & 22,2 & 22,2 & 70,5 \\
\hline & $56-65$ & 67 & 17,5 & 17,5 & 88,0 \\
\hline & over 66 & 46 & 12,0 & 12,0 & 100,0 \\
\hline & total 1 & 383 & 100,0 & 100,0 & \\
\hline
\end{tabular}

(Table 4). The disabled and people suffering from chronic diseases spend the lion's share of the spending on pharmaceuticals, on the drugs needed for treatment of their diseases; besides, these people usually fall under the category of consumers with low income.

Different characteristics of consumers, such as their health, age and income, showed general tendencies but did not disclose higher or lower degree of consumer vulnerability. With correlation coefficient being from 0,070 to 0,632 (Table 2), all the character- istics could be included into one model as none of them distorted the general picture of the model. Such integrated study of correlations enabled to reveal current and essential tendencies of consumer vulnerability. It was established that elderly consumers with low income (who live on pension or social allowances) and with higher than predisposition to illness, which is usually related to older age or disability, constitute the most socially vulnerable part of consumers. Seeking to protect them from irrational drug consump- 
Table 4. Distribution of consumers according to their income and purpose of purchased pharmaceuticals

\begin{tabular}{|l|c|c|c|c|}
\hline & \multicolumn{2}{|c|}{$\begin{array}{c}\text { Persons with low and } \\
\text { very low income }\end{array}$} & \multicolumn{2}{c|}{$\begin{array}{c}\text { Persons with high and } \\
\text { very high income }\end{array}$} \\
\hline Purpose & Frequency & Percent & Frequency & Percent \\
\hline $\begin{array}{l}\text { Treatment of the disability and chronic } \\
\text { diseases }\end{array}$ & 108 & 18,2 & 2 & 1,3 \\
\hline Treatment of acute and other diseases & 376 & 63,4 & 34 & 21,3 \\
\hline Maintaining good health & 46 & 7,8 & 33 & 58,1 \\
\hline Giving up harmful habits & 19 & 3,2 & 3 & 1,9 \\
\hline Body care & 44 & 7,4 & 28 & 17,5 \\
\hline Total & 593 & 100,0 & 160 & 100,0 \\
\hline
\end{tabular}

tion and to prevent increase of economic vulnerability, when high spending on pharmaceuticals limit their ability to purchase other goods, the Baltic countries have introduced drug subsidizing system. This way the most socially vulnerable group of pharmaceutical consumers is protected, and that is confirmed by the correlation between age and expenses on pharmaceuticals: just a small part $(3,2 \%)$ of consumers over 66 years of age incur high expenses when purchasing pharmaceuticals. However, while the most vulnerable consumer group is protected, other consumer groups are exposed to intensive promotion which influences their decisions and that fosters growth of consumer vulnerability. Meanwhile consumer opinion polls suggest that doctors' and pharmacists' influence on consumers' decisions is rather insignificant. Such influence was established only in $46 \%$ of cases (Table 5), and therefore it is assumed that only in less than half situations drugs were prescribed professionally. These findings suggest a different picture from the one that health care professionals themselves have: they tend to overestimate their influence on consumers. Specialists believe that over $70 \%$ of purchases are influenced by them, of which about $20 \%$ are made up by doctors' prescriptions and about $50 \%$ when consumers followed pharmacists' advice.

Seeking to evaluate consumer vulnerability according to two most important criteria - side effect of drugs and drugs inaccessibility, consumers had to answer the questions whether they had ever experienced adverse reactions to drugs and how often they did not manage to buy necessary drugs due to shortage of money. Side effects of drugs were revealed only in 5,2\% of cases, but then specific knowledge and equipment is needed to diagnose that; and even $31 \%$ of respondents admitted that they had failed to purchase necessary drugs due to shortage of money (Table 6).

In order to assess vulnerability of every consumer group, model summary was drawn up. Linear model enabled to measure weight of each factor and its importance to consumer vulnerability. As the study shows, consumer vulnerability is most influenced by 5 factors: age, sex, health, expenses on pharmaceuticals and annual income per capita (Table 7). Three models of consumer vulnerability could be analyzed. The first one (a) is best reflected by age and sex, of which adjusted $\mathrm{R}$ square is higher than 0,4 , i.e. $40 \%$ of variations can be explained by these two variables. In order to better understand the reasons of consumer vulnerability, the second and third models should be analyzed. In the second model (b) adjusted R square is higher than 0,6 , and in the third model (c) it is almost 0,8 . That means that the data on 5 characteristics of pharmaceutical consumers may account for almost $80 \%$ of vulnerability indicator variation. Other indicators which reflect certain characteristics of

Table 5. The main influences that determine choice of pharmaceuticals

\begin{tabular}{|l|c|c|c|}
\hline & Pharmacists' estimation & Doctors' estimation & Consumer survey \\
\hline Doctors' prescriptions & 9,004 & 54,759 & 21,456 \\
\hline Pharmacists' advice & 62,055 & 20,531 & 23,965 \\
\hline Brand awareness & 5,892 & 11,137 & 14,51 \\
\hline Advertising & 20,286 & 13,242 & 34,506 \\
\hline Other people's advice & 2,763 & 0,331 & 5,5607 \\
\hline
\end{tabular}


Table 6. Distribution of consumers according to noticed adverse reactions and possibility to purchase necessary drugs

\begin{tabular}{|c|c|c|c|c|c|c|c|}
\hline & & Frequency & Valid percent & $\begin{array}{c}\text { Cumulative } \\
\text { percent }\end{array}$ & Frequency & Valid percent & $\begin{array}{c}\text { Cumulative } \\
\text { percent }\end{array}$ \\
\hline Gender & Males & 14 & 29,8 & 100,0 & 134 & 43,8 & 100,0 \\
\hline \multirow[t]{6}{*}{ Age } & under 25 & 5 & 10,6 & 10,6 & 35 & 11,4 & 11,4 \\
\hline & $26-35$ & 6 & 12,8 & 23,4 & 55 & 18,0 & 29,4 \\
\hline & $36-45$ & 8 & 17,0 & 40,4 & 84 & 27,5 & 56,9 \\
\hline & $46-55$ & 9 & 19,1 & 59,6 & 44 & 14,4 & 71,2 \\
\hline & $56-65$ & 6 & 12,8 & 72,3 & 35 & 11,4 & 82,7 \\
\hline & over 66 & 13 & 27,7 & 100,0 & 53 & 17,3 & 100,0 \\
\hline \multirow[t]{5}{*}{ Annual income $(000 \bullet)$} & under 3 & 12 & 25,5 & 25,5 & 114 & 37,3 & 37,3 \\
\hline & $3-10$ & 17 & 36,2 & 61,7 & 115 & 37,6 & 74,8 \\
\hline & $10-20$ & 11 & 23,4 & 85,1 & 44 & 14,4 & 89,2 \\
\hline & $20-30$ & 6 & 12,8 & 97,9 & 23 & 7,5 & 96,7 \\
\hline & over 30 & 1 & 2,1 & 100,0 & 10 & 3,3 & 100,0 \\
\hline \multirow[t]{5}{*}{$\begin{array}{l}\text { Monthly spending on } \\
\text { pharmaceuticals, }\end{array}$} & under 50 & 8 & 17,0 & 17,0 & 83 & 27,1 & 27,1 \\
\hline & $50-100$ & 7 & 14,9 & 31,9 & 72 & 23,5 & 50,7 \\
\hline & $100-150$ & 8 & 17,0 & 48,9 & 57 & 18,6 & 69,3 \\
\hline & $150-200$ & 12 & 25,5 & 74,5 & 57 & 18,6 & 87,9 \\
\hline & over 200 & 12 & 25,5 & 100,0 & 37 & 12,1 & 100,0 \\
\hline
\end{tabular}

Table 7. Model Summary on pharmaceutical consumer vulnerability

\begin{tabular}{|c|c|c|c|c|}
\hline Model & R Square & R Square & Adjusted R Square & $\begin{array}{c}\text { Std. Error } \\
\text { of the Estimate }\end{array}$ \\
\hline 1 & $0,664 \mathrm{a}$ & 0,441 & 0,44 & 0,1535 \\
\hline 2 & $0,834 \mathrm{~b}$ & 0,695 & 0,695 & 0,1133 \\
\hline 3 & $0,891 \mathrm{c}$ & 0,794 & 0,793 & 0,0934 \\
\hline 4 & $0,896 \mathrm{~d}$ & 0,802 & 0,801 & 0,0915 \\
\hline 5 & $0,897 \mathrm{e}$ & 0,805 & 0,804 & 0,0908 \\
\hline
\end{tabular}

a) Predictors: (Constant): age, gender

b Predictors: (Constant): age, gender, health

c) Predictors: (Constant): age, gender, health, spending on pharmaceuticals, annual income per head in the family or per capita

d) Predictors: (Constant)): age, gender, health, spending on pharmaceuticals, annual income per head in the family or per capita, spending on pharmaceuticals

e) Predictors: (Constant): age, gender, health, annual income per head in the family or per capita, purpose of purchased pharmaceuticals, education, occupation, marital status, ethnic origin, region of residence.

consumers, such as purpose of the purchased pharmaceuticals, education, employment, marital status, ethnic status, region or residence, etc., have no significant role in the study of pharmaceutical consumer vulnerability.

On the basis of the survey results groups of consumers were singled out, which have different vulnerability degree that depends on pharmaceutical con- sumption and pharmaceutical consumer vulnerability. The most vulnerable consumer group consists of people aged 46-65, with annual income under 3,000 - and the least vulnerable group are people aged 3645 , with annual income over $20,000 \bullet$. Vulnerability indicator fluctuated from 0,003 to 0,695 . Integrated indicator of pharmaceutical consumption and pharmaceutical consumer vulnerability in the Baltic countries is 0,2061 (Table 8). 
Table 8. Pharmaceutical consumer vulnerability according to consumer groups

\begin{tabular}{|c|c|c|c|c|c|c|c|}
\hline \multicolumn{5}{|c|}{ Characteristics of consumer group } & \multirow{2}{*}{$\begin{array}{l}\text { Minimal } \\
\text { weight in } \\
\text { the group }\end{array}$} & \multirow{2}{*}{$\begin{array}{l}\text { Maximum } \\
\text { weight in } \\
\text { the group }\end{array}$} & \multirow{2}{*}{$\begin{array}{l}\text { Average in } \\
\text { the group }\end{array}$} \\
\hline Age & $\begin{array}{l}\text { Spending on } \\
\text { pharmaceuticals } \\
\text { per month, } €\end{array}$ & Gender & $\begin{array}{l}\text { Annual income } \\
\text { p.p, } €\end{array}$ & Health $^{\mathrm{a}}$ & & & \\
\hline under 25 & $<30-50$ & women & $<15000-20000$ & 2 & 0,003 & 0,003 & 0,003 \\
\hline $26-35$ & $>10$ & women & $<3000-10000$ & 2 & 0,003 & 0,003 & 0,003 \\
\hline $26-35$ & $<10-30$ & women & $<15000-20000$ & 1 & 0,003 & 0,003 & 0,003 \\
\hline $36-45$ & $>10$ & women & $<3000-10000$ & 1 & 0,003 & 0,003 & 0,003 \\
\hline $36-45$ & $<30-50$ & women & $<3000-10000$ & 5 & 0,003 & 0,015 & 0,003 \\
\hline $36-45$ & $<30-50$ & men & $<20000$ & 2 & 0,003 & 0,003 & 0,003 \\
\hline $56-65$ & $<70$ & men & $<3000-10000$ & 5 & 0,003 & 0,003 & 0,003 \\
\hline under 25 & $<70$ & men & $>10000$ & 1 & 0,003 & 0,005 & 0,003667 \\
\hline $26-35$ & $<30-50$ & men & $<15$ 000- 20000 & 2 & 0,003 & 0,005 & 0,0046 \\
\hline $56-65$ & $<50-70$ & women & $<3000-10000$ & 2 & 0,005 & 0,015 & 0,008333 \\
\hline \multicolumn{8}{|l|}{$\ldots$} \\
\hline $56-65$ & $<30-50$ & men & $<3000-10000$ & 5 & 0,503 & 0,503 & 0,503 \\
\hline $46-55$ & $<10-30$ & men & $>3000$ & 5 & 0,216 & 0,6 & 0,5232 \\
\hline over 66 & $<70$ & women & $<3000-10000$ & 5 & 0,399 & 0,676 & 0,5583 \\
\hline $26-35$ & $<30-50$ & men & $<10000-15000$ & 3 & 0,6 & 0,6 & 0,6 \\
\hline $36-45$ & $<50-70$ & men & $<15000-20000$ & 4 & 0,6 & 0,6 & 0,6 \\
\hline $46-55$ & $<50-70$ & women & $>3000$ & 3 & 0,6 & 0,6 & 0,6 \\
\hline $46-55$ & $<70$ & men & $>3000$ & 5 & 0,6 & 0,6 & 0,6 \\
\hline $56-65$ & $>10$ & women & $<3000-10000$ & 3 & 0,6 & 0,6 & 0,6 \\
\hline $56-65$ & $<50-100$ & women & $<10000-15000$ & 2 & 0,6 & 0,6 & 0,6 \\
\hline $56-65$ & $<30-50$ & men & $<10000-15000$ & 4 & 0,6 & 0,6 & 0,6 \\
\hline $56-65$ & $<50-70$ & men & $<10000-15000$ & 2 & 0,6 & 0,6 & 0,6 \\
\hline $36-45$ & $<70$ & women & $>3000$ & 6 & 0,674 & 0,674 & 0,674 \\
\hline over 66 & $<70$ & women & $<15000-20000$ & 5 & 0,674 & 0,674 & 0,674 \\
\hline $46-55$ & $<50-70$ & women & $<10000-15000$ & 5 & 0,503 & 0,887 & 0,695 \\
\hline \multicolumn{5}{|l|}{ All groups } & 0,003 & $\mathbf{0 , 8 8}$ & 0,2061 \\
\hline
\end{tabular}

\section{Discussion}

The results of the study confirm and extend conclusions of the recent researches conducted in different fields of consumption. The results reveal the major reasons of pharmaceutical consumer vulnerability inherent in the Baltic countries and enable to assess possibilities to reduce such vulnerability in view of transformational period characteristics. The study suggests that one of the main factors determining the degree of pharmaceutical consumer vulnerability is age: vulnerability of consumers aged 46-65 is several times higher than in other age groups. Brengman, Geuens and De Pelsmacker [19], who analysed perception of commercial information, concluded that women over the age of 35 are more vulnerable than 
younger representatives of the same socio-economic group. In this study, as in the previous studies [20], gender was found also to be one of the most important characteristics: women are more vulnerable to the misleading influence of promotion in pharmaceutical consumption than men. Van Wyk and Mason [21], who studied brand confusion and assessed factors that determine consumer socialization and risky behavior, also confirmed higher vulnerability of aging people. Not all consumers manage to successfully adapt to the changing situation and growing flow of information and that causes their higher vulnerability. Economic damage and social vulnerability are very important aspects in the Baltic countries, which are still undergoing transformational period. A characteristic feature of the most vulnerable group of pharmaceutical consumers in the Baltic countries is the tendency to self-treatment. Specialists - doctors and pharmacists - have little influence on this group of consumers - only $46 \%$ of purchases are made under their influence.

Essential differences between vulnerability of consumers and different demographic - economic status constitute an important subject for further research. High degree vulnerability of consumers of certain age may be determined by natural aging, changing system of values and perception of the surroundings, as well as by impact of socio-technological surroundings experienced at one or another period of life. Thus, a big difference in vulnerability between consumers of different age but with the same social and economic status shows a new direction of research, i.e. research into different age groups, which could help reveal the main reasons of why some age groups exhibit high vulnerability while others do not.

This study is the first time when an integrated methodology was applied to develop the indicator of pharmaceutical consumption and pharmaceutical consumer vulnerability that helped to estimate vulnerability of different consumer groups and consumer vulnerability on the Baltic countries scale. The Baltic countries are undergoing processes of rapid integration into Western economic, social and cultural life, and the degree of pharmaceutical consumer vulnerability is seen as a major factor showing their potential to fully integrate into Western world. Consumer vulnerability was studied in the pharmaceutical market of the Baltic countries, which has been market-socially oriented for 14 years. Pharmaceutical consumer vulnerability in all three Baltic countries is similar; geographical factor and ethnicity, apparently, do not have much significance determining pharmaceutical consumer vulnerability. The indicator of the estimated pharmaceuti- cal consumption and pharmaceutical consumer vulnerability in all three Baltic countries is 0.172 . The weight of the indicator is not high, if compared to maximum $(\mathrm{Cmax}=1)$, but to understand its implication it has to be compared to the relevant indicators of other countries. Research into pharmaceutical consumer vulnerability is advisable to be conducted on international/regional scale, so that to establish social-geographic zones which pose the highest economic and health threat to consumers. Findings of such research could not only be beneficial as indicators of the country's/region's social welfare, but also help to develop partnerships of various international healthcare organizations.

What could be viewed, as a drawback of the study is the decision to estimate different factors that influence consumers separately, whereas in practice, marketing specialists of pharmaceutical companies seek synergetic effect by simultaneously employing several forms of promotion.

\section{References}

1. RAMIREZ, P. The globalisation of research in the pharmaceutical industry: A case of uneven development. Technology Analysis \& Strategic Management, 2006, 18 (2), p. 143-167.

2. VASAN, A.; HOOS, D.; MUKHERJEE, J. S.; FARMER, P. E.; ROSENFIELD, A. G.; PERRIĖNS, J. H. The pricing and procurement of antiretroviral drugs: an observational study of data from the Global Fund. Bulletin of the World Health Organization, 2006, 84 (5), p. 393-398.

3. COULTER, A. R.; PRICE, L. L.; FEICK, L. Rethinking the origins of involvement and brand commitment: insights from postsocialist central Europe. Journal of Consumer Research, 2003, 30 (2), p. 151-69.

4. McCABE, S. E. Illicit use of prescription pain medication among college students. Drug Alcohol Depend, 2005, Jan 7; 77 (1), p. 37-47.

5. WESTERLUND, L. T. Nonprescription drug-related problems and pharmacy interventions. The Annals of pharmacotherapy, 2001, Nov, 35 (11), p. 1343-1349.

6. BITTEN, N.; STEVENSON, F. A.; BARRY, C. A.; BARBER, N.; BRADLEY, C. P. Misunderstandings in prescribing decisions in general practice: qualitative study. British Medical Journal, 2000, Feb 19, 320, p. 484-488.

7. GEORGE, B.; HARRIS, A.; MITCHELL, A. Costeffectiveness analysis and the consistency of decision making: evidence from pharmaceutical reimbursement in Australia (1991 to 1996). PharmacoEconomics, 2001, Nov, 19 (11), p. 1103-1009. 
8. Van den BEMT P.; POSTMA, M. J.; van ROON, E. N.; CHOW, M. C.; FIJN, R.; BROUWERS, J. Costbenefit analysis of the detection of prescribing errors by hospital pharmacy staff. Drug Safety, 2002, Jan, 25 (2), p. 135-143.

9. PETROVA, G. I. Monitoring of national drug policies - regional comparison between Bulgaria, Romania, Macedonia, Bosnia Herzegovina. Central European Journal of Public Health, 2001, Nov, 9 (4), p. 205.

10. BATAVIA, A. I. and BEAULAURIER, R. L. The Financial Vulnerability of People with Disabilities: Assessing Poverty Risk. Journal of Sociobiology and Social Welfare, 2001, 1, p. 139-162.

11. HIBBERT, D.; BISSELL, P. and WARD, P. R. Consumerism and Professional Work in the Community Pharmacy. Sociology of Health and Illness, 2002, 1 (24), p. 46-65.

12. LEE, J. and SOBERON-FERRER, H. Consumer Vulnerability to Fraud: Influencing factors. The Journal of Consumer Affairs, 1997, 1 (31).

13. BENETS, S.; PITTS; R. E. and LaTOUR, M. The Appropriateness of Fear Appeal use for Health Care Marketing to the Elderly: Is It OK to Scare Granny? Journal of Business Ethics, 1993, January, p. $45-55$.

14. ANDREASEN, A. R. and MANNING, J. The Dissatisfaction and Complaining behavior of Vulnerable Consumers. Journal of Consumer Satisfaction/Dissatisfaction and Complain Behavior, 1990, 3, p. 12-20.
15. MORGAN, F. W.; SCHULER, D. K. and STOLTMAN, J. J. A Framework for Examining the Legal Status of Vulnerable Consumers. Journal of Public Policy and Marketing, 1995, 14, p. 267-277.

16.SMITH, C. N. and COOPER-MARTIN, E. Ethics and Target Marketing: The Role of Product Harm and Consumer Vulnerability. Journal of Marketing, 1997, 61 (3), p. 1-20.

17. RINGOLD, D. J. Vulnerability in the Marketplace: Concepts, Caveats, and Possible Solutions. Journal of Macromarketing, 2005, 25 (2), p. 202-214.

18. WIDDUS, R. Public-private Partnerships for Health: Their Main Targets, the Diversity, and Their Future Directions. Bulletin of the World Health Organization, 2001, 79 (8), p. 713-720.

19. BRENGMAN, M. and GEUENS, M. The Impact of Consumer Characteristics and Campaign Related in Print Advertising. Journal of Marketing Communications, 2001, 7, p. 231-243.

20. CORREA-DE-ARAUJO, R; MILLER, G. E.; BANTHIN, J. S.; TRINH, Y. Gender differences in drug use and expenditures in a privately insured population of older adults. Journal of Women's Health, 2005, Feb, 14 (1), p. 73-81.

21. VAN WYK, J. and MASON, K. A. Investigating Vulnerability and Reporting Behavior for Consumer Fraud Victimization: Opportunity as a Social Aspect of Age. Journal of Contemporary Criminal Justice, 2001, 17 (4), p. 328-346. 